\title{
A atuação do dentista de familia na pandemia do Covid-19: o cenário do Rio de Janeiro*
}

\section{| ${ }^{1}$ Amanda Firme Carletto, ${ }^{2}$ Felipe Fernandes dos Santos |}

\author{
1 Instituto de Medicina Social, Universidade do Estado do Rio de Janeiro. Rio de Janeiro-RJ, Brasil (amandacarletto@gmail.com). \\ ORCID: 0000-0002-4984-5018 \\ 2Escola Politécnica de Saúde Joaquim Venâncio, Fundação Oswaldo Cruz. Rio de Janeiro-RJ, Brasil (felipefernandes@vivario.org.br). \\ ORCID: 0000-0002-4845-8788 \\ Recebido em: 09/06/2020 \\ Aprovado em: 16/06/2020 \\ Revisado em: 24/06/2020
}

DOI: http://dx.doi.org/10.1590/S0103-73312020300310

$\mathrm{Na}$ perspectiva internacional, os sistemas públicos de saúde têm um perfil de assistência odontológica predominantemente privada, com forte influência neoliberal (CHAVES et al., 2018). No cenário brasileiro, o acesso aos serviços odontológicos públicos está previsto dentro do Sistema Único de Saúde (SUS) por meio da Atenção Básica (AB) integrada aos Centros de Especialidades Odontológicas (CEOs) e aos Laboratórios Regionais de Prótese Dentária criados em 2004 pelo "Brasil Sorridente".

$\mathrm{O}$ atendimento odontológico no Brasil é caracterizado historicamente pela livre demanda do paciente/usuário e baseado em açóes curativas e/ou mutiladoras em uma ótica tipicamente flexneriana. A formação odontológica ainda é centrada em um modelo biologicista, curativo e organizado em espaços privados (consultório/ clínica odontológica), de acesso individual e segmentado. Estas características, que definem a formação e o atendimento no setor privado, são reproduzidas, de modo geral, nos serviços públicos de saúde (MARTELLI et al., 2010).

\footnotetext{
* Nossos agradecimentos ao professor Ronaldo Teodoro, em formato de saudaçôes sanitaristas democráticas pela orientação para construção deste texto.
} 
Este estudo vem compartilhar a reflexão sobre a atuação dos dentistas de família durante a pandemia do Covid-19 no cenário brasileiro e expor a ponderação da atual competência técnica com a real possibilidade de ampliação do escopo de trabalho, desde que legalmente respaldado, para contribuir de forma marcante no combate ao SARS-CoV-2. No entanto, antes de situarmos essa condição sanitária dos dentistas de família, inseridos na perspectiva da Política Nacional da Atenção Básica (PNAB), faremos um breve levantamento da sua trajetória de construçáo dentro do SUS.

Há um marcante descompasso entre uma Odontologia que atua em uma lógica de mercado, individual e tecnicista, com as propostas das políticas de saúde do SUS. A Odontologia Sanitária é considerada um ramo da Saúde Pública responsável pelo diagnóstico e tratamento dos problemas de saúde oral da comunidade por meio do trabalho organizado dentro do território para resolver os problemas e obter as melhores condições possíveis de saúde oral (NARVAI, 2006).

Apesar de o Programa de Saúde da Família (PSF) ter sido criado em 1994, a inserção dos profissionais de saúde bucal com incentivo financeiro só aconteceu em 2000 com a instituição da Portaria Ministerial no 1.444 (BRASIL, 2000), regulamentada em 2001 pela Portaria no 267. A Portaria no 267, que estabeleceu o Plano de Reorganização das Ações de Saúde Bucal na AB, instituiu as estratégias de incorporação da saúde bucal no PSF descrevendo as atribuições comuns e específicas a cada categoria da equipe; as responsabilidades institucionais dos entes federados; o financiamento; e a descrição dos procedimentos preconizados para a Atenção Básica (BRASIL, 2001).

Em 2004, em um cenário de priorização de políticas inclusivas e após muitas lutas para a ampliação do acesso à saúde bucal pública e garantia de uma rede de assistência odontológica, houve a criação do "Brasil Sorridente", com a atualização da Política Nacional de Saúde Bucal (PNSB), que é considerada um marco na saúde bucal brasileira porque reorganizou a saúde bucal do primeiro nível de atenção, principalmente por meio das Equipes de Saúde Bucal (ESB) na Estratégia Saúde da Família (ESF), e qualificou a atenção especializada por meio da criação dos CEOs. Com isto, o Brasil passou a ter crescente incentivo à implantação da Saúde Bucal na ESF; aumentou a oferta dos serviços odontológicos básicos e especializados e o acesso à água fluoretada; e melhorou os indicadores de saúde bucal em todo país, apesar de ainda persistirem diferenças regionais e sociais marcantes com maior severidade para o interior do Norte e Nordeste (CHAVES et al., 2017). 
O Brasil avançou da situação de "país dos banguelas" por seu perfil mutilador até o final do século XX, para a redução da doença cárie (patologia bucal mais comum), com a expansão marcante da cobertura de saúde bucal na $\mathrm{AB}$ e dos serviços especializados. No quesito ampliaçáo de acesso, de 2003 a 2006 houve crescimento de $254 \%$ das equipes de saúde bucal, 398\% dos CEOs e de 12,49 da cobertura da primeira consulta odontológica; de 2007 a 2010, esse crescimento foi de 35,4\%; $71,3 \%$ e 13,6\%, respectivamente. De 2011 a 2014, houve certa estabilização com apenas $18,7 \%$ de crescimento percentual de equipes de saúde bucal na ESF, 20,8\% dos CEOs e $12,8 \%$ da primeira consulta (CHAVES et al., 2017).

De acordo com Scarparos et al. (2015), no estado do Rio de Janeiro houve ampliação dos serviços odontológicos por meio da extensão das equipes de saúde bucal dentro da $\mathrm{AB}$ nos moldes da ESF e da atenção especializada com os CEOs, de 2004 a 2010. Com relação aos municípios que ofertavam os serviços, em 2004 havia 4,35\% dos municípios com CEO; 34,78\% com equipe de saúde bucal; e 13,04\% com água fluoretada. Em 2010, a ampliação levou à cobertura de 45,65\%; 79,35\% e $33,7 \%$, respectivamente.

Segundo estudo realizado por Chaves et al. (2018) sobre a saúde bucal brasileira no período de 2015 a 2017, houve importante diminuição da implantação das ESB, e então do financiamento, da cobertura e do acesso à primeira consulta odontológica. De 2015 a 2016, houve redução de 83 equipes de saúde bucal e aumento de 3,6\% dos CEOs. Em 2017, houve aumento de 6,2\% da implantação de equipes em relação a 2016.

Para Narvai (2017), o Programa "Brasil Sorridente", reconhecido internacionalmente, está em risco eminente de ser extinto. A saúde bucal pública sofre grandes ameaças junto ao SUS desde 2016 com o golpe da Dilma Rousseff e início do governo Temer, com a aprovação da EC 95 (que reduz por duas décadas os recursos para a Educação e a Saúde), e com a desregulamentação dos repasses federais por meio da diminuição de seis para dois dos blocos de financiamento do SUS, e por fim, em 2017 com a nova PNAB (Portaria no 2.436), que flexibiliza a gestão do município de maneira a abrir a possibilidade de organização do sistema local sem implantação da assistência odontológica básica. Além disso, a PNAB de 2017 possibilita clara indução para a extinção dos auxiliares de saúde bucal (ASB), com a mudança dos tipos de modalidade de equipe permitindo formar equipes apenas com os dentistas e técnicos de saúde bucal (TSB). 
Em seu texto, Narvai (2017) destaca a necessidade de persistência política da defesa da saúde bucal como direito universal e como parte indispensável para a integralidade do cuidado em saúde, em contraponto aos interesses corporativistas. Desde 2017, encontra-se em tramitação o Projeto de Lei no 6836, que depende da aprovação do Senado e da sanção presidencial para tornar o "Brasil Sorridente" uma lei federal, o que será um respaldo importantíssimo para que a assistência odontológica brasileira não seja extinta e continue na luta da ampliação do acesso.

Em conexão com esse cenário de desmonte dos direitos sociais em saúde, em setembro de 2019, com o desgoverno do presidente Bolsonaro, houve a aprovação da Portaria $n^{\circ} 2.539$, que alterou o incentivo financeiro e flexibilizou a carga horária das ESBs do padrão de 40 horas para 20 e 30 horas, afetando diretamente o modelo assistencial em saúde bucal. Ao invés de investir na formação odontológica para o SUS, o Governo Federal novamente incentivou o retorno para o modelo biomédico tradicional, com clara indução de expansão do mercado odontológico privado, colocando em risco o processo de trabalho que vem sendo construído, e assim, o acesso à saúde bucal pública de qualidade, universal e integral (BRASIL, 2019a).

Em novembro de 2019, com a implementação da Portaria no 2.979, houve outro grande ataque do atual desgoverno ao caráter universal do SUS e à democracia brasileira, com a mudança radical do modelo de custeio da $\mathrm{AB}$ com alteração dos critérios do Piso de Atenção Básica (PAB) fixo e variável para financiamento focado no número de pessoas registradas e cadastradas; pagamento por desempenho; e incentivos financeiros para açôes e programas prioritários definidos pelo Governo Federal (BRASIL, 2019b). Correlato a esse movimento, o desafio da saúde bucal já não foge à regra da saúde frente à corrente neoliberal do Estado, mesmo com todos os avanços, a saúde bucal ainda está muito voltada para a lógica do capital, distanciandose novamente das necessidades humanas. Supóe-se que haverá extensão do trabalho (super) especializado e privado com exigências de habilidades individuais e técnicas avançadas que garantam uma autonomia sobre o cuidado em saúde. A "Revolução" odontológica perpassa a superação dessa perspectiva, ao aplicar o conhecimento técnico-científico alinhado às reais necessidades da população.

Em tempos de pandemia do Covid-19, em meio a uma agenda da saúde que possui como pauta o desmonte e desaparelhamento do SUS, é necessário fortalecer as lutas. Desta forma, a motivação para estudar o trabalho do dentista de família 
em tempos de pandemia se torna um cerne na discussão de valorização da categoria frente a uma proposta de inserção alinhada a sua capacidade técnica de atuaçáo e de sua identificação enquanto membro de uma equipe de saúde multiprofissional e coletiva na Atenção Primária em Saúde (APS).

A atuação do dentista na APS nos moldes da ESF é regida pela PNAB e pela PNSB, e possui um desenho bem delimitado dentro da equipe de saúde bucal, junto ao auxiliar de saúde bucal e/ou com o técnico de saúde bucal (TSB). A equipe de saúde bucal é vinculada à equipe da ES, e, portanto, o profissional dentista, além da responsabilidade com a vigilância sanitária e epidemiológica e de gestão do setor, realiza atendimentos clínicos em consultório por meio de escuta e acolhimento de avaliaçôes clínicas, demandas programadas e urgências/emergências; participa de reuniōes de equipe; realiza grupos de educação em saúde; faz visitas domiciliares; e orientaçóes individuais e coletivas. Além disso, o dentista trabalha de forma articulada com as demandas do território junto às equipes e com instituiçôes de ensino da área adscrita na qual realiza as atividades do Programa de Saúde na Escola (PSE).

\section{O dentista de família na pandemia}

Desde março de 2020, com o advento da pandemia pelo novo coronavírus (Covid-19), as ESB estáo desempenhando um novo trabalho dentro das equipes por recomendaçôes municipais, do Ministério da Saúde, da ANVISA, do Conselho Federal de Odontologia e de outras instituiçôes de ensino. Os documentos publicados por essas instituições norteiam a atuação dos profissionais de saúde, incluindo o trabalho da equipe de saúde bucal da APS.

A Agência Nacional de Vigilância Sanitária (ANVISA) publicou notas técnicas que têm sido atualizadas com o decorrer da pandemia. Nessas notas ficaram estabelecidas regras para a assistência odontológica, inclusive diferenciando os cuidados em diferentes cenários: consultório/ambulatório, o ambiente hospitalar e a unidade de terapia intensiva (UTI). O documento da ANVISA restringiu os procedimentos odontológicos ao atendimento de urgências e emergências; deu ênfase aos cuidados com a anamnese criteriosa, com a sala de espera e com os equipamentos de proteção individual (EPI); e recomendou a realização de bochecho com peróxido de hidrogênio 01 a 1,5\% prévio ao atendimento e o uso prioritário de dispositivos manuais ao atender para evitar gerar aerossóis (BRASIL, 2020a). 
A proposta "O Brasil Comigo", coordenada pelos ministérios da Saúde e Educação, disponibilizou uma capacitação com Protocolos de Manejo Clínico do Coronavírus (Covid-19) que incluiu o cenário das unidades básicas de saúde (UBS), mas não fez abordagens específicas por categoria profissional, sem citação para o novo formato de trabalho dos dentistas de família (BRASIL, 2020b).

O Ministério da Saúde (MS) publicou o documento "Atendimento odontológico no SUS", em março de 2020, na qual a ESB foi incluída como equipe de triagem e classificação dos usuários suspeitos de estarem infectados pelo vírus junto às equipes, inclusive, por meio do "fast track Covid-19", podendo colaborar na notificação dos casos juntamente com a equipe de enfermagem. O MS delineou o cancelamento dos atendimentos eletivos e a manutenção das urgências e emergências com necessidade de tomar os cuidados com os EPI e anamnese criteriosa antes dos atendimentos. Nesse documento, o uso da máscara N95 foi indicada apenas para atendimento clínico de usuários com sintomas de infecção respiratória, diferentemente da recomendação da ANVISA, que indica o uso de N95 ou equivalente para o ambiente ambulatorial (BRASIL, 2020c,d).

O Conselho Federal de Odontologia (CFO) publicou duas versôes sobre recomendaçôes para atendimento odontológico durante a pandemia do Covid-19, a versão atualizada (junho de 2020) flexibilizou o atendimento eletivo para casos de pessoas sem suspeita para Covid-19 sem estabelecer intervalo mínimo para essas consultas e liberou o uso de máscara cirúrgica nos atendimentos em caso de escassez de EPIs (BRASIL, 2020e).

Em maio houve a publicação do Observatório Covid-19 da Fundação Oswaldo Cruz, "Recomendaçóes para a organização da APS no SUS no enfrentamento da Covid-19”, com orientação sobre a organização da UBS, das açôes de vigilância e de segurança do usuário e do trabalhador, a promoção da saúde e a organização do cuidado na rede de atenção (ENGSTROM et al., 2020).

A Coordenação Técnica de Saúde Bucal do município do Rio de Janeiro publicou uma Nota Técnica, em março de 2020, sobre as recomendaçóes de manejo odontológico na qual recomendou que a ESB deve permanecer na UBS no trabalho conjunto com as equipes, auxiliando na identificação de pessoas com síndrome gripal que procurem a unidade. $\mathrm{O}$ documento trouxe a descrição da precaução-padrão com o diferencial importante do uso de máscara N95 ou PFF2 exclusivamente para procedimentos que gerem aerossóis e determinou o intervalo 
de consultas de uma hora entre os atendimentos clínicos, dentre outras várias recomendaçōes (RIO DE JANEIRO, 2020).

Sobre o processo de trabalho, o município do Rio de Janeiro, alinhado à recomendação nacional, manteve os atendimentos de urgência e emergência e suspendeu os turnos de atividade coletiva e atendimentos eletivos, com a exceção dos atendimentos individuais para gestantes em acompanhamento na APS. Neste momento de pandemia, foi preconizado que o pré-natal odontológico seja realizado por meio de procedimentos que não gerem aerossóis, salvo os casos de emergência. Os casos de suspeita de câncer oral foram tratados como prioridade; por isso, devem ser encaminhados aos estomatologistas dos CEOs (RIO DE JANEIRO, 2020).

A precaução mais relevante e discutida entre os profissionais de saúde é a correta utilização dos EPIs, sem os mesmos não há possibilidade de atuação, uma vez que o risco de contaminação e disseminação do vírus se torna evidente, para além das incertezas inerentes a um novo vírus ainda em estudo. Também está preconizado que o dentista de família deve fazer o acolhimento e a escuta inicial dos casos de síndrome gripal e a colaborar no monitoramento junto às equipes. Além disso, é possível apoiar nas campanhas de vacinação, realizar orientaçôes a usuários tabagistas e a outros grupos de risco que comparecem aos atendimentos e executar outras atividades que as equipes avaliem como necessárias nesse cenário.

Dentre as atribuiçôes, destaca-se que o dentista de família pode: 1) contribuir com a gestão, capacitação e manipulação de EPI, pois esta categoria tem histórica experiência com a utilização obrigatória e cotidiana de máscara, gorro, luvas e jaleco para a realização de todos os procedimentos clínicos; 2) realizar o teste RT-PCR (do inglês reverse-transcriptase polymerase chain reaction), porque os dentistas possuem forte domínio da área anatômica contemplada e realizam procedimentos clínicos invasivos rotineiramente; 3) diagnosticar e fazer intervenção medicamentosa dos casos de síndrome gripal, já que possuem hábito e respaldo técnico de diagnosticar e prescrever uma amplo leque de medicamentos; 4) atuar diretamente no acompanhamento da saúde bucal e sensibilidade gustativa dos casos positivos em monitoramento, juntamente com a equipe médica e de enfermagem, colaborando com as investigaçôes da recente doença.

Com os documentos norteadores disponíveis, é possível identificar algumas semelhanças nas recomendaçóes para a atuação do dentista durante a pandemia; persistem, entretanto, algumas distinçóes que são destacáveis e condizentes com os 
interesses específicos das instituiçôes. A equipe de saúde bucal encontra-se em um panorama de grande exposição ao vírus, por isso deve lutar para que o trabalho seja realizado com a proteção adequada, resguardando o usuário e o trabalhador.

O retrato do trabalho real do cirurgiáo-dentista na $A B S$ e seu subaproveitamento na linha de frente do combate ao coronavírus (Covid-19), bem como atitudes e práticas nesse cenário permitiram uma reflexão sobre a atuação do dentista a partir de um contexto mais amplo e ativo. A formação desse roteiro e novo itinerário remete a uma abordagem de construção de conhecimento a partir de necessidades de saúde das pessoas neste momento histórico. Valer-se disso requer pensar a concretude da atuação desse trabalhador, sua importância e sua relevância no contexto de pandemia.

\section{Considerações finais}

As políticas austeras desconsideram as necessidades humanas, valorizam o custoefetividade de serviços essenciais e fundamentais para o processo saúde-doença, colaborando para o adoecimento social de uma população. Com a eleição municipal de 2020 e o prolongado tempo de paralização do setor privado odontológico, há a hipótese de que os gestores municipais estejam realizando pressão para o retorno dos atendimentos odontológicos eletivos no SUS, mesmo sem respaldo técnico para isto, e há clara flexibilização dos atendimentos eletivos por parte do CRO (até mesmo sem o EPI perenizado pela ANVISA) para que a retomada da economia do setor privado.

A saúde bucal brasileira segue sofrendo prejuízos por conta de políticas austeras e de caráter financeiro. O escopo de atuação dos dentistas de família brasileiros está restrito e precisa ser revisto, há demanda e respaldo técnico que justificam a atuação mais abrangente destes profissionais no combate ao Sars-Cov-2. Por uma questão de responsabilidade sanitária e social frente ao cenário de pandemia, os Dentistas de Família devem assumir uma postura marcante no combate ao Covid-19. O esvaziamento dessa categoria no combate à Covid-19 frente ao cenário caótico necessita ser discutido e repensado.

Com os 16 anos de existência do "Brasil Sorridente" é indiscutível que houve ampliação da rede de assistência odontológica, consequente dilatação do acesso dos cidadãos brasileiros aos cuidados em saúde bucal e avanços na formação e prática em saúde bucal, mas existem desafios importantes que tem se agravado com a irresponsabilidade sanitária do estado. É preciso reformular a atuação do ente federal enquanto indutor de políticas sociais, das universidades públicas enquanto 
formadoras de profissionais para o SUS e do modelo assistencial odontológico em tempo de pandemia. Como os desafios do Covid-19 tem nos mostrado, é necessário redescobrir novos territórios conceituais e explorar práticas inovadoras para superar parte do paradigma ainda hegemônico de atenção odontológica brasileira restrita a procedimentos clínicos e ao atendimento centrado na cadeira do dentista.

\section{Referências}

BRASIL. Ministério da Saúde. Gabinete do Ministro. Portaria GM/MS no 1.444/00, de 28 de dezembro de 2000. Estabelece incentivo financeiro para a reorganização da atenção à saúde bucal prestada nos municípios por meio do Programa de Saúde da Família. Diário Oficial da Uniāo, Brasília, DF, p. 85, 29 dez. 2000.

. Ministério da Saúde. Gabinete do Ministro. Portaria no 267/GM de 6 de março de 2001. Diário Oficial da União, Brasília-DF, p. 67, 7 mar. 2001

. Ministério da Saúde. Gabinete do Ministro. Portaria no 2.539 de 27 de setembro de 2019. Diário Oficial da União, Brasília-DF, p. 164, 27 set. 2019a.

. Ministério da Saúde. Política Nacional da Atenção Básica. Brasília, 2017. Portaria no 2.436, de 21 de setembro de 2017. Aprova a Política Nacional de Atenção Básica, estabelecendo a revisão de diretrizes para a organização da Atenção Básica, no âmbito do Sistema Único de Saúde (SUS). Diário Oficial da União. 21 set 2017.

. Ministério da Saúde. Portaria no 2.979, de 12 de novembro de 2019. Institui o Programa Previne Brasil, que estabelece novo modelo de financiamento de custeio da Atençáo Primária à Saúde no âmbito do Sistema Único de Saúde (SUS). Diário Oficial da União, BrasíliaDF, p. 97, 13 nov. 2019 b.

- Ministério da Saúde. Secretaria de Atenção Primária à Saúde (SAPS). Atendimento Odontológico no SUS. Brasília-DF, mar. 2020c.

- Ministério da Saúde. Secretaria de Atenção Primária à Saúde (SAPS). Fluxograma atendimento odontológico. Brasília-DF, mar. 2020d.

NOTA TÉCNICA GVIMS/GGTES/ANVISA no 04/2020. Orientaçóes para serviços de saúde: medidas de prevenção e controle que devem ser adotadas durante a assistência aos casos suspeitos ou confirmados de infecção pelo novo coronavírus (sars-CoV-2). Rio de Janeiro: ANVISA, maio, 2020a. Disponível em: <www.anvisa.gov.br> Acesso em: maio 2020.

Ministério da Saúde. Portaria no 492 de 23 de março de 2020. Institui uma Ação Estratégica "O Brasil Conta Comigo", voltada aos alunos dos cursos da área de saúde, para o enfrentamento à pandemia do coronavírus (Covid-19). Diário Oficial da União, Brasília-DF, ed: 56-C; Seção: 1 - Extra, p. 4, 23 mar. 2020b. 
CHAVES, S. C. L. et al. Política de Saúde Bucal no Brasil 2003-2014: cenário, propostas, ações e resultados. Ciênc. saúde coletiva, Rio de Janeiro, v. 22, n. 6, p. 1791-1803, 2017. . Política de Saúde Bucal no Brasil: as transformações no período 2015-2017. Saúde em Debate, v. 42, p. 76-91, 2018.

CONSELHO FEDERAL DE ODONTOLOGIA. Recomendações AMIB/CFO para atendimento odontológico Covid-19: Comitê de Odontologia AMIB/CFO de enfrentamento ao COVID-19. Departamento de Odontologia AMIB - 2º Atualização 01/06/2020, BrasíliaDF. 2020e.

ENGSTROM, E. et al. Recomendaçóes para a organização da Atenção Primária à Saúde no SUS no enfrentamento da Covid-19. Rio de Janeiro: FIOCRUZ, maio 2020.

MARTELLI, P. J. L. et.al. Perfil do cirurgião-dentista inserido na Estratégia de saúde da Família em municípios do estado de Pernambuco, Brasil. Ciênc. Saúde Coletiva. Rio de Janeiro, v. 15, supl. 2, p. 3243-3248, 2010.

NARVAI, P. C. O fim do Brasil Sorridente? Jornal Odonto. Brasil, n. 238, 17 ago. 2017. Disponível em: <https://www.jornaldosite.com.br/materias/artigos\&cronicas/anteriores/ paulo\%20capel/artcapel238.htm>. Acesso em: 7 jun. 2020.

- Saúde Bucal Coletiva: caminhos da odontologia sanitária à bucalidade. Revista de Saúde Pública, v. 40, n. esp., p. 141-7, 2006.

RIO DE JANEIRO (MUNICÍPIO). Prefeitura Municipal do Rio de Janeiro. Secretaria Municipal de Saúde. Coordenadoria Técnica de Saúde Bucal. Nota Técnica SMS-RJ, n. 2/2020. Rio de Janeiro, mar. 2020.

SCARPARO, A. et al. Impacto da Política Nacional de Saúde Bucal - Programa Brasil Sorridente - sobre a provisão de serviços odontológicos no Estado do Rio de Janeiro. Cad. saúde colet., Rio de Janeiro, v. 23, n. 4, p. 409-415, dez. 2015. 